\section{MECHANICAL CIRCULATORY SUPPORT IN A PATIENT WITH CONGENITALLY CORRECTED TRANSPOSITION OF THE GREAT ARTERIES}

\section{To the Editor:}

We read with interest the case report by Huang and Slaughter, ${ }^{1}$ recently published in The Journal of Thoracic and Cardiovascular Surgery. The article summarizes surgical experience with left ventricular assist device (LVAD) therapy implementation in a patient with congenitally corrected transposition of the great arteries (ccTGA) who experienced end-stage heart failure due to failure of the systemic ventricle.

We agree with Huang and Slaughter $^{1}$ that patients with ccTGA present unique challenges for VAD implantation and management because of their individual anatomical features and sequelae of previous palliations (adhesions, prosthetic valves in situ, and residual intracardiac shunts).

Based on our experience with such patients, VAD insertion into the systemic, but anatomically and morphologically right, ventricle has been feasible using different cannulation sites: the free wall or diaphragmal surface. ${ }^{2}$ Because of the thickness of the wall of the failing ventricle, with its enlarged cavity, we did not place silicon rings as "spacers" for reduction of the intracavital part of the inflow cannula.

Individuals with a significantly increased risk for intraoperative bleeding and firm intrathoracic adhesions

\footnotetext{
The Editor welcomes submissions for possible publication in the Letters to the Editor section that consist of commentary on an article published in the Journal or other relevant issues. Authors should: - Include no more than 500 words of text, three authors, and five references. - Type with double-spacing. - See http://jtcs.ctsnetjournals.org/misc/ifora.shtml for detailed submission instructions. - Submit the letter electronically via jtcvs.editorialmanager.com. Letters commenting on an article published in the JTCVS will be considered if they are received within 6 weeks of the time the article was published. Authors of the article being commented on will be given an opportunity of offer a timely response ( 2 weeks) to the letter. Authors of letters will be notified that the letter has been received. Unpublished letters cannot be returned.
}

after palliations may benefit from the off-pump insertion technique described by Huebler et $\mathrm{al}^{2}$ from our working group, which eliminates the bleeding risk related to the cardiopulmonary bypass. However, appropriate determination of the optimal insertion point for the inflow cannula and the detection of thrombi and additional chordae or other inflow obstacles using preoperative computed tomographic scan imaging and intraoperative transesophageal echocardiography guidance are crucial.

Our patient, a 59-year-old man with ccTGA, dextrocardia, pulmonary artery stenosis, a ventricular septal defect, and a secundum-type atrial septal defect, had undergone 2 complex palliation procedures in the past. He is still receiving ongoing support over 24 months after HeartWare HVAD (Framingham, Mass) insertion was performed using the off-pump approach and placement of the inflow cannula via the diaphragmal surface of the systemic ventricle. ${ }^{2}$

Alexander Stepanenko, MD Evgenij V. Potapov, MD, PhD

Roland Hetzer, MD, PhD

Department of Cardiothoracic and Vascular Surgery

Deutsches Herzzentrum Berlin Berlin, Germany

\section{References}

1. Huang J, Slaughter MS. HeartWare ventricular assist device placement in a patient with congenitally corrected transposition of the great arteries. J Thorac Cardiovasc Surg. 2013;145:e23-5

2. Huebler M, Stepanenko A, Krabatsch T, Potapov EV, Hetzer R. Mechanical circulatory support of systemic ventricle in adults with transposition of great arteries. ASAIO J. 2012;58:12-4.

http://dx.doi.org/10.1016/ j.jtcvs.2013.02.082

\section{Reply to the Editor:}

We want to thank Stepanenko et al for their interest in our report ${ }^{1}$ on placement of a HeartWare ventricular assist device (HVAD) in a patient with congenitally corrected transposition of great arteries (ccTGA). The Berlin group has reported and described the concerns that need to be addressed when considering a VAD for patients with ccTGA. ${ }^{2,3}$

We agree with Stepanenko et $\mathrm{al}^{2}$ that careful consideration needs to be given to inflow cannula/pump placement. We chose to use a needle with injection of agitated saline to verify the best possible orientation. As noted by Stepanenko et al, it is possible to implant VADs “off pump." However, this limits the surgeon's ability to inspect the ventricle for thrombus, crossing fibers, or other anatomical variations that might cause inflow obstruction. Thus, it was our opinion that it is best to have a short run on cardiopulmonary bypass to closely inspect the ventricular cavity because it is morphologically a right ventricle with many more trabeculations and possible sites for thrombus formation.

Patients with congenital heart disease present with unique challenges for mechanical assist device placement. A variety of surgical techniques should be available to the surgeons because the anatomical and pathological features of the defective heart might be different for each patient. VAD cannulation site selection and position must be determined with accuracy and verified by echocardiography and pump performance before leaving the operating room.

Long-term HVAD support, as described in our report and in the patients of Stepanenko et al, ${ }^{2}$ demonstrates the possibility of using VAD support as an alternative treatment option for ccTGA patients with end-stage heart failure either as a bridge to transplant or destination therapy.

Jiapeng Huang, MD, PhD Mark Slaughter, MD

Jewish Hospital University of Louisville

Louisville, Ky

\section{References}

1. Huang J, Slaughter MS. HeartWare ventricular assist device placement in a patient with congenitally corrected transposition of the great arteries. J Thorac Cardiovasc Surg. 2013;145:e23-5. 